\title{
Cosmetics Use-Related Adverse Events and Determinants Among Jigjiga Town Residents, Eastern Ethiopia
}

Arebu I. Bilal · Zelalem Tilahun · Ebrahim D. Osman · Anwar Mulugeta ·

Muktar Shekabdulahi · Derbew Fikadu Berhe

Received: October 12, 2016 / Published online: November 23, 2016

(C) The Author(s) 2016. This article is published with open access at Springerlink.com

\section{ABSTRACT}

Introduction: Non-medicated cosmetics use is very common among the Ethiopian population. However, little is known about these products' related adverse events. The aim of this study was to assess the prevalence and determinants of cosmetics-related adverse events among Jigjiga Town residents, Eastern Ethiopia.

Enhanced content To view enhanced content for this article go to http://www.medengine.com/Redeem/ 3327F060494B214C.

A. I. Bilal $(\bowtie) \cdot$ Z. Tilahun

Department of Pharmaceutics and Social Pharmacy, College of Health Sciences, School of Pharmacy, Addis Ababa University, Addis Ababa, Ethiopia e-mail: arebu.issa@aau.edu.et

\section{E. D. Osman}

Department of Pharmacy, Jigjiga Health Sciences

College, Jigjiga, Ethiopia

A. Mulugeta

Department of Pharmacology, College of Health

Sciences, School of Medicine, Addis Ababa

University, Addis Ababa, Ethiopia

M. Shekabdulahi

Department of Public Health, College of Medicine and Health Sciences, Jigjiga University, Jigjiga,

Ethiopia

D. F. Berhe

Department of Pharmacy, College of Health

Sciences, Mekelle University, Mekelle, Ethiopia
Methods: A community-based cross-sectional study design was conducted in May and June 2014. Semi-structured interviews were used to collect cosmetics use pattern and related adverse events. For assessing determinants, logistic regression was used and statistical significance was set at $p<0.05$.

Results: Overall, 600 participants were approached with a $93 \%$ response rate. Ninety-three percent $(n=521)$ of them reported the use of cosmetics at least once within 2 weeks prior to this study, and of these, 229 (44\%) used traditional herbal cosmetics along with modern cosmetics. A total of 342 (61\%) reported experiencing adverse events of which the most common reported were: allergic reactions, 149 (36\%); the appearance of acne, 66 (16\%); and hirsutism, 52 (12.5\%). The occurrence of cosmetics-related adverse events were significantly associated with the number of cosmetics used per day, the frequency of use, mixing of different types of cosmetics together, and mixing of cosmetics with water or saliva.

Conclusion: A higher proportion of cosmetic users reported experiencing at least one adverse event. The number of cosmetic products and frequency of use were important predictors for 
experiencing adverse events. This implies the need to consider safety concerns related to cosmetic use. Approaches to address such issues may include awareness creation programs and promoting the concept of cosmetovigilance among cosmetic sellers, users, and other stakeholders.

Keywords: Adverse cosmetic events; Cosmetics; Cross-sectional study; Ethiopia; Jigjiga

\section{INTRODUCTION}

Cosmetics are preparations intended to be applied to the human body for cleansing, beautifying, promoting attractiveness or altering the appearance without affecting the body's structure or functions [1]. The increasing demand of consumers' desire to be "good looking" and little societal awareness towards safety of these products has resulted in increasing cosmetics utilization [2-4]. Despite social perception of their safety and tolerability, during recent decades there is evidence for harmful effects of these products [5-7]. Globally, reported numbers of adverse events are so far very low [8]. This underestimation can be mainly attributed to self-diagnosis, self-use (medication), and the absence of medical consultation, particularly by users may not recognize or give attention to mild and moderate harmful events [8]. In addition, underestimation of such harmful effects may be because of the absence of formal and reliable monitoring systems ('cosmetovigilance') being in place [9]. Altogether, this results in extremely low reporting rates even in a global context $[2,9,10]$.

In the western world, most countries have laws and regulations on cosmetic safety and labeling; however, in developing countries, including Ethiopia, cosmetics do not need marketing authorization unlike for medicinal products [11]. The drug regulatory system pays little attention to protecting the public against the harmful effects emanating from these products, as is also true in many other countries [12-16]. In addition, some consumers did not read labels in order to identify the ingredients and other useful information on the cosmetic products before deciding to use them $[17,18]$. A study conducted in Jimma Town in Ethiopia revealed that products tested for their skin reaction showed not only the presence of negligible skin irritancy but also the presence of prohibited ingredients in all the products tested [11]. Another study conducted among university students reported that a significant number of students complained of different forms of adverse effects from cosmetics $[19,20]$.

The high level of illiteracy and loose regulations as well as the climatic conditions where the country is situated means that we should expect more potential interactions of topically applied cosmetic products with UV light $[11,21]$. In Ethiopia, non-medicated cosmetics use is very common in society [11]. It can be speculated that there will be numbers of unreported potentially harmful and severe incidents caused by cosmetics. Therefore, the aim of this study was to assess the prevalence and determinants of cosmetic-related adverse events among Jigjiga Town residents, Eastern Ethiopia.

\section{METHODS}

\section{Study Design and Set-Up}

A community-based cross-sectional study was conducted in Jigjiga Town, the capital of the Somali regional state of Ethiopia. The town has ten Kebeles (the smallest administrative unit) and four of them were included in this study. 
The study was carried out from May to June 2014

\section{Study Population}

Participants' inclusion criteria were adults ( $\geq 18$ years) who had lived in the town at least for 6 months prior to our data collection period. Four Kebeles were selected by using simple random sampling; the numbers of households (HH) were proportionally allocated to the four Kebeles, based on the size of the Kebeles. A systematic random sampling technique was used to include every 5th $\mathrm{HH}$, and subsequently one eligible adult member from each $\mathrm{HH}$ was randomly selected.

The main outcome variables were experiencing cosmetic-related adverse events (yes/no) and the different types, as claimed by participants. Expected adverse events were defined and listed on the data collection tool. Participants were also given the option to mention if they did found a matching phrase for the adverse event(s) they experienced.

Potential determinates for the outcome variables were (1) socio-demographic characteristics, (2) frequency of cosmetics use, (3) number of cosmetics used, (5) use of traditional herbal cosmetics, and (6) ways of cosmetics use.

\section{Operational Definitions}

\section{Traditional Herbal Cosmetics}

These are homemade cosmetics prepared from indigenous herbs in the study area.

\section{Modern Cosmetics}

Manufactured, packed and labeled by international or national companies and commercially available in the local markets.

\section{Data Source and Collection Procedure}

Data were collected via interviews using a pre-tested semi-structured questionnaire. Participants were interviewed for (1) socio-demographic variables, (2) cosmetic use (yes/no) and, (3) cosmetic-related adverse events. The tool was prepared in English and translated into local languages using standard procedures. Data collectors had a health science background supervised by principal investigators.

\section{Sample Size Calculation}

A single population proportion formula was used for the sample size calculation required for the study. Due to the lack of prior data, sample size was estimated based on $50 \%$ prevalence at $95 \%$ confidence interval and $4 \%$ degrees of freedom. The final sample size was 600 .

\section{Compliance with Ethical Standards}

The Institutional Ethical Review Board of the School of Pharmacy, Addis Ababa University, gave permission to conduct the survey, and discussions about the aim and purpose of the survey was carried out with Jigjiga Woreda Health Office, while, finally, informed consent was obtained from each study participant before conducting the interview.

\section{Data Entry and Analysis}

Descriptive statistics were used to summarize the nature and frequency of cosmetic use. Bivariate and multivariate logistic regression analyses were applied to investigate the determinants of cosmetic use associated with adverse events. All explanatory variables 
associated with the outcome variable in the bivariate analysis with $p<0.20$ were included in the multivariate logistic regression model. Epi info 3.5.1 and SPSS v.20 for Windows prram were used for the data entry and analysis, respectively. Statistical significance was set at $p<0.05$.

\section{RESULTS}

Among the 600 HHs approached, 559 were covered which gives a 93\% response rate. The majority of the study participants were female, 424 (76\%). More than half of the respondents, $310(55.5 \%)$, were within the age group of 18-20 years. Nearly three-quarters of them were single. A total of 520 (93\%) of them had used cosmetics within 2 weeks prior to the interview date. Among these, 280 (54\%) claimed to use cosmetics for cleansing purposes, 100 (19\%) for beautification, $76(14.6 \%)$ for protection from sunlight, and 29 (5.5\%) as medication. Shampoo was the most commonly used cosmetic type with 182 (33\%), followed by deodorant, $153(27 \%)$, and face powder, 90 $(16 \%)$. A to tal of (44\%) of the respondents have used traditional herbal cosmetics along with the modern cosmetics (Table 1).

A total of 342 (61\%) had claimed to experience adverse events among which three-quarters were by females. The most frequently reported subjective symptoms were: allergic reactions, 149 (36\%); acne, 66 (16\%); hirsutism, 52 (12.5\%); skin thinning, 40 (9.6\%); hair breakage, 35 (8.4\%); and face and other body parts skin soreness, 31 (7.4\%) (Fig. 1). Among those who reported to experience adverse events, 121 (35.4\%) consulted health care providers while 92 (27\%) stopped using the cosmetics for some time but when the adverse events disappeared they started using them again, $74 \quad(21.6 \%)$ stopped using other cosmetic products which had similar contents, and $64(18.7 \%)$ stopped using any kind of cosmetics. Most of the study participants, 481 (92\%), collected their cosmetic products from either supermarkets or shops.

\section{Determinants for Experiencing Adverse Events}

Adverse event experiences were directly associated with age. Older aged participants (21-30 years old) tended to claim experiencing less adverse events compared with the youngest ones (16-20 years old), (AOR 0.59; 95\% CI 0.34-0.90). The association seemed to be similar in age groups greater than 31 years of age; however, the association did not show statistical significance (AOR 0.49; 95\% CI 0.208-1.22). Higher educational status (college or university) increased the chance of reporting adverse events compared with non-literate participants $(\mathrm{AOR}=2.77 ; 95 \%$ CI 1.11-7.00). However, middle level education (primary or secondary) did not show any association with reporting of adverse events. In the bivariate model, participants with lower monthly incomes tend to report adverse events compared with those with higher incomes (COR 0.50; 95\% CI 0.28-0.90). However, in the multiple regressions model, there was no significant difference by income. The occurrences of an adverse event show a significant association with occupation with self-employed and unemployed participants being less likely to report adverse events compared to housewives (AOR 0.30; 95\% CI $0.10-0.80$ ) and (AOR 0.11; 95\% CI 0.02-0.52), respectively. Other variables including gender and marital status did not show statistically significant associations with the occurrence of adverse events (Table 2). 
Table 1 Socio-demographic and cosmetics use in 559 respondents, among Jigjiga Town residents, Ethiopia

\begin{tabular}{l} 
Variables \\
\hline Gender \\
Female \\
Age (years) \\
$18-20$ \\
$21-30$ \\
$31-40$ \\
Marital status \\
Single \\
Married \\
Ethnicity \\
Guragae \\
Somali \\
Amhara \\
Oromo \\
Educational background \\
Non-literate \\
Primary level \\
Secondary level \\
College/university \\
Occup
\end{tabular}

Occupation

Housewives

$64(11)$

Student

$369(66)$

Government-employed

Self-employed

Unemployed

Income (monthly) in Ethiopian birr

$$
\begin{aligned}
& <1000 \\
& 1001-2000 \\
& 2001-3000 \\
& >3001
\end{aligned}
$$

$265(47)$

$88(16)$

$55(10)$

Type of cosmetic used

Shampoo

$182(33)$
Table 1 continued

\begin{tabular}{lr}
\hline Variables & $\boldsymbol{n}(\%)$ \\
\hline Deodorant & $153(27)$ \\
Face powder & $90(16)$ \\
Lipstick & $89(16)$ \\
Hair cosmetics & $86(15)$ \\
Tooth paste & $78(14)$ \\
Eye makeup & $74(13)$ \\
Skin colorant & $54(10)$ \\
Nail polishing & $39(7)$ \\
Soaps & $6(1)$ \\
Purpose of use & \\
Cleansing & $280(50)$ \\
Beautification & $100(18)$ \\
Protection & $76(14)$ \\
Whitening & $24(4)$ \\
Hair coloring & $6(1)$ \\
Anti-aging & $6(1)$ \\
Herbal cosmetics used together with modern & $246(44)$ \\
cosmetics & \\
\hline
\end{tabular}

\section{Cosmetics Utilization Characteristics} and Occurrence of Cosmetics Related Adverse Events

Those who used cosmetics for special occasions $(\mathrm{AOR}=0.60 ; \quad 95 \% \quad$ CI $0.36-0.99) \quad$ or only sometimes (0.65; 95\% CI 0.37-1.14) had less likelihood of reporting adverse cosmetic events as compared to daily users. The use of traditional herbal cosmetics did not show a significant association with experiencing adverse cosmetic events. Participants who used different types of cosmetics by mixing them had a twofold likelihood in experiencing adverse cosmetic events compared to those who used cosmetics without mixing $(\mathrm{AOR}=1.98 ; 95 \% \mathrm{CI}$ 


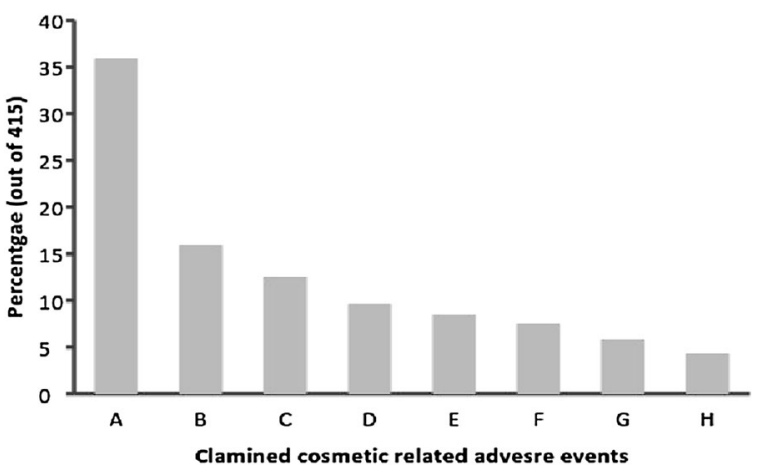

Fig. 1 Percentage of cosmetics-related adverse events reported by participants in Jigiiga Town in June 2014. Total number claimed was 415 (there were participants who reported more than one adverse event). $A$ allergic reactions; appearance of acne; hirsutism; $D$ skin thinning; $E$ hair breakage; $F$ skin soreness; $G$ discoloration of face; $H$ skin thinning

1.18-3.20). In addition, those who used cosmetics by mixing with water or saliva were more likely to experience adverse events $(\mathrm{AOR}=5.83 ; 95 \%$ CI 2.64-12.87). Frequency of cosmetic use per day also showed a significant association with claiming related adverse events. Those who used cosmetics twice daily had a two times greater likelihood of experiencing adverse events compared to those who used a specific cosmetics once per day $(\mathrm{AOR}=2.27 ; 95 \% \mathrm{CI} 1.21-4.24)$. Those who used cosmetics three times and more than three times showed a significant association as compared to those who used them once per day $\quad(\mathrm{AOR}=1.82 ; \quad 95 \% \quad \mathrm{CI} \quad 1.00-3.39)$ and $(\mathrm{AOR}=1.92 ; 95 \%$ CI 1.03-3.57), respectively. The number of cosmetics products used per day showed a significant association with the experience of cosmetic-related adverse events, as the number of cosmetic products used per day increases the odds of experiencing an increase in adverse events, and the association is statistically significant (Table 3 ).

\section{DISCUSSION}

The number of participants who reported experiencing adverse cosmetic events was higher as compared to studies conducted in other parts of Ethiopia [19, 20], and in other countries such as the Netherlands (12\%) [22], UK (12\%) [23], Nepal (24\%) [8], and Rio de Janeiro (38\%) [24]. This can be explained partly by the low level of literacy in the study area, and also the little priority given to non-medicated cosmetic use safety evaluation and laboratory assessments in Ethiopia [11, 21]. Geographically, our study area is one of the warmest places in Ethiopia. In such an area, cosmetic storage and handling may require special care and protection; however, in realty, most cosmetic sales outlets lacks proper storage. In Ethiopia, including our study area, most cosmetic outlet sellers are not professionals but are also not educated. This may result in improper storage and sale of products, product exposure to sunlight, and inappropriate handling of products as compared to cosmetics from drug retail outlets [20].

In this study, females reported a higher number of adverse events, and this finding is in line with a study conducted in Nepal [8]. Allergic reactions and acne were the most commonly reported cases, and similar types of adverse events were also reported in other studies [19, 20]. Younger age participants reported more adverse events which could be due to the high consumption rate by this age group, as has been reported in Malaysia, and also better awareness of cosmetics-related adverse events as age increases [18]. A study conducted in Nepal documented that only one-quarter of the patients with cosmetic-related adverse events consulted 
Table 2 Factors affecting occurrence of adverse events among household respondents in Jigiga Town, June 2014 ( $n=559$; $95 \% \mathrm{CI})$

\begin{tabular}{|c|c|c|c|c|}
\hline & Yes & No & Crude odds ratio & Adjusted odds ratio \\
\hline \multicolumn{5}{|l|}{ Gender } \\
\hline Male & 85 & 50 & 1.00 (reference) & 1.00 (reference) \\
\hline Female & 257 & 167 & $0.95(0.60-1.35)$ & $0.85(0.53-13.6)$ \\
\hline \multicolumn{5}{|l|}{ Age } \\
\hline $18-20$ & 204 & 106 & 1.00 & 1.00 \\
\hline $21-30$ & 125 & 94 & $0.70(0.48-0.98)^{*}$ & $0.59(0.34-0.90)^{*}$ \\
\hline$>31$ & 13 & 17 & $0.40(0.18-0.84)^{*}$ & $0.49(0.20-1.22)$ \\
\hline \multicolumn{5}{|l|}{ Marital status } \\
\hline Married & 71 & 51 & 1.00 & 1.00 \\
\hline Single & 271 & 166 & $1.17(0.78-1.76)$ & $0.94(0.54-1.64)$ \\
\hline \multicolumn{5}{|l|}{ Educational status } \\
\hline Non-literate & 28 & 26 & 1.00 & 1.00 \\
\hline Primary level & 57 & 35 & $1.51(0.76-2.98)$ & $0.84(0.33-2.00)$ \\
\hline Secondary education & 172 & 126 & $1.26(0.79-2.26)$ & $0.60(0.26-1.42)$ \\
\hline College/universities & 85 & 30 & $2.63(1.33-5.17)^{*}$ & $2.77(1.11-7.00)^{*}$ \\
\hline \multicolumn{5}{|l|}{ Income in Ethiopian birr } \\
\hline$\leq 1000$ & 174 & 91 & 1.00 (reference) & 1.00 (reference) \\
\hline $1001-2000$ & 85 & 66 & $0.67(0.44-1.06)$ & $0.68(0.43-1.06)$ \\
\hline $2001-3000$ & 56 & 32 & $0.915(0.55-1.51)$ & $0.98(0.52-1.83)$ \\
\hline$\geq 3001$ & 27 & 28 & $0.50(0.28-0.90)^{*}$ & $0.56(0.28-1.11)$ \\
\hline \multicolumn{5}{|l|}{ Occupation } \\
\hline Housewives & 38 & 26 & 1.00 & 1.00 \\
\hline Student & 237 & 132 & $1.22(0.71-2.11)$ & $1.12(0.49-2.55)$ \\
\hline Government-employed & 49 & 27 & $1.24(0.62-2.46)$ & $0.58(0.22-1.47)$ \\
\hline Self-employed & 15 & 20 & $0.51(0.22-1.18)$ & $0.30(0.10-0.80)^{*}$ \\
\hline Unemployed & 3 & 12 & $0.17(0.04-0.66)^{*}$ & $0.11(0.02-0.52)^{*}$ \\
\hline
\end{tabular}

* Significant at $p<0.05$ multivariate logistic regression

health care providers [8]; however, one-third of our study participants with adverse events did so, which would seem to suggest that many complaints were of a (reasonably) serious nature. In line with other studies, most reported adverse events in this study were related to sites of cosmetic application on the body [22, 23].

Low adverse event reporting by participants with lower educational status can be explained 
Table 3 Cosmetics utilization pattern and occurrence of cosmetics related adverse events in Jigiga Town, June 2014 $(n=521 ; 95 \% \mathrm{CI})$

\begin{tabular}{|c|c|c|c|c|}
\hline & \multicolumn{2}{|c|}{ Adverse event } & \multicolumn{2}{|l|}{ Odds ratio $(\mathrm{OR})$} \\
\hline & Yes & No & Crude & Adjusted \\
\hline \multicolumn{5}{|l|}{ Frequency of use } \\
\hline Daily & 225 & 99 & 1.00 & 1.00 \\
\hline For special occasions & 61 & 48 & $0.56(0.36-0.88)^{*}$ & $0.60(0.36-0.99)^{*}$ \\
\hline Sometimes & 52 & 36 & $0.63(0.40-1.03)^{*}$ & $0.65(0.37-1.14)$ \\
\hline \multicolumn{5}{|c|}{ Concomitant use of herbal product cosmetics } \\
\hline No & 77 & 166 & 1.00 & 1.00 \\
\hline Yes & 106 & 172 & $1.32(0.92-1.90)$ & $0.75(0.50-1.14)$ \\
\hline \multicolumn{5}{|l|}{ Main selection criteria for use } \\
\hline Affordability & 58 & 35 & 1.00 & 1.00 \\
\hline Quality & 273 & 120 & $1.37(0.86-2.20)$ & $1.25(0.73-2.13)$ \\
\hline Accessibility & 7 & 28 & $0.15(0.60-0.38)^{*}$ & $0.12(0.04-0.34)^{*}$ \\
\hline \multicolumn{5}{|c|}{ Number cosmetic products used per day } \\
\hline 1 & 34 & 32 & 1.00 (references) & 1.00 (references) \\
\hline $2-4$ & 256 & 117 & $2.05(1.21-3.50)$ & $1.46(1.21-1.67)^{*}$ \\
\hline $5-6$ & 32 & 30 & $1.00(0.50-2.00)$ & $1.64(1.10-6.28)^{*}$ \\
\hline Greater than 6 & 4 & 16 & $3.76(1.13-12.46)^{*}$ & $2.56(1.55-4.26)^{*}$ \\
\hline \multicolumn{5}{|l|}{ Frequency of use daily } \\
\hline Once & 85 & 49 & 1.00 & 1.00 \\
\hline Twice & 115 & 81 & $0.82(0.52-1.30)$ & $2.27(1.21-4.24)^{*}$ \\
\hline Three times & 101 & 43 & $1.40(0.82-2.23)$ & $1.82(1.00-3.39)^{*}$ \\
\hline More than three times & 37 & 10 & $2.13(0.976-4.66)$ & $1.92(1.03-3.57)^{*}$ \\
\hline \multicolumn{5}{|c|}{ Expenditure on cosmetics per month } \\
\hline$\leq 500$ & 239 & 133 & 1.00 & 1.00 \\
\hline $501-1000$ & 75 & 37 & $1.12(0.72-1.76)$ & $0.91(0.53-1.57)$ \\
\hline $1001-1500$ & 10 & 5 & $1.11(0.37-3.32)$ & $0.87(0.22-3.45)$ \\
\hline$\geq 500$ & 14 & 8 & $0.97(0.39-2.38)$ & $0.56(0.19-1.65)$ \\
\hline \multicolumn{5}{|l|}{ Cosmetics way of use } \\
\hline Use them separately & 145 & 112 & 1.00 & 1.00 \\
\hline Mix them as such & 141 & 54 & $2.00(1.35-3.00)^{*}$ & $1.98(1.18-3.20)^{*}$ \\
\hline Mix them with water or saliva & 52 & 17 & $2.362(1.29-4.30)^{*}$ & $5.83(2.64-12.87)^{*}$ \\
\hline
\end{tabular}

* Significant at $p<0.05$ multivariate logistic regression 
in two ways. First, it could be because cultural, religious or social factors for low cosmetic use. The second is that they may experience an adverse event but were not able to identify what it was and whether it was caused by the cosmetics product they used. In line with previous reports $[19,20]$, the frequency of use of cosmetic products was an important predictor for experiencing an adverse event. In addition, the use of multiple cosmetics has a significant association with adverse event experience. This could be partly explained by interaction between cosmetic products or a synergistic effect of the products to each other.

Participants who used water or saliva for mixing were more likely to experience adverse events. Mixing cosmetic products with media not described by the manufacturer may result in a change in the physical and chemical property of the product or may produce unintended chemical reactions, which may result in unexpected adverse events. In addition, water and saliva are suitable media for bacterial growth can will also affect the concentrations of the preservatives $[19,25]$. Use of traditional herbal cosmetics in our study did not show a significant association with experiencing adverse events; however, a number of studies have reported increased adverse events with their use [20, 26-31].

\section{Limitation of the Study}

This study may suffer from unmeasured confounders such as the duration of exposure to the cosmetics and UV light. Participants' medical illnesses and medication history were also not within the scope of this study. Such factors are, however, known to have interactions with cosmetic products. Since the majority of our study participants were female, the prevalence contraceptive- or cosmetic use-induced adverse events needs further potential interaction study.
Some of the adverse events reported by our study participants may not necessarily have been caused by the cosmetic product they used. This needs further investigation for causality assessment, which was beyond the scope of this study.

\section{CONCLUSIONS}

A higher proportion of cosmetic users reported experiencing at least one adverse event. The number of cosmetic products and their frequency of use were important predictors for experiencing adverse events. This implies the need to consider cosmetic product use-related safety concerns. Approaches to address such an issue may include awareness creation programs and promoting the concept of cosmetovigilance among cosmetic sellers, users, and other stakeholders.

\section{ACKNOWLEDGEMENTS}

No funding or sponsorship was received for this study or the publication of this article. All named authors meet the International Committee of Medical Journal Editors (ICMJE) criteria for authorship for this manuscript, take responsibility for the integrity of the work as a whole, and have given final approval for the version to be published.

Disclosures. Arebu I. Bilal, Zelalem Tilahun, Ebrahim D. Osman, Anwar Mulugeta, Muktar Shekabdulahi and Derbew Fikadu Berhe declare that they have no conflict of interest.

Compliance with Ethics Guidelines. The Institutional Ethical Review Board of the School of Pharmacy, Addis Ababa University, gave permission to conduct the survey, and discussions about the aim and purpose of the 
survey was carried out with Jigjiga Woreda Health Office, while, finally, informed consent was obtained from each study participant before conducting the interview.

Data Availability. The datasets during and/ or analyzed during the current study are available from the corresponding author on reasonable request.

Open Access. This article is distributed under the terms of the Creative Commons Attribution-NonCommercial 4.0 International License (http://creativecommons.org/licenses/ by-nc/4.0/), which permits any noncommercial use, distribution, and reproduction in any medium, provided you give appropriate credit to the original author(s) and the source, provide a link to the Creative Commons license, and indicate if changes were made.

\section{REFERENCES}

1. Ethiopian Food, Medicine and Healthcare Administration and Control Authority (FMHACA). Cosmetics and Sanitary Items Directive. 2014. http://www.fmhaca.gov.et/documents/Cosmetics $\% 20$ and\%20Sanitary\%20Items\%20Directive.pdf. Accessed Jan, 2014.

2. Sautebin L. Understanding the adverse effects of cosmetics: a pilot project in cosmetovigilance. Drug Saf. 2008;31(5):433-6.

3. Bedi MK, Shenefelt PD. Herbal therapy in dermatology. Arch Dermatol. 2002;138:232-42.

4. Eisenburg DM, Kessler RC, Foster C, et al. Unconventional medicine in the United States: prevalence, costs and pattern use. N Engl J Med. 1993;328:246-52.

5. Berne B, Lundin A, Enander Malmros I. Side effects of cosmetics and toiletries in relation to use. A retrospective study in a Swedish population. Eur J Dermatol. 1994;4:189-93.

6. Orton DI, Wilkinson JD. Cosmetic allergy: incidence, diagnosis, and management. Am J Clin Dermatol. 2004;5:327-37.
7. Willis CM, Shaw S, De Lacharriere O, et al. Sensitive skin: an epidemiological study. Br J Dermatol. 2001;145:258-63.

8. Giovanni CD, Arcoracid V, Gambardella L. Cosmetovigilance survey: are cosmetics considered safe by consumers. Pharmacol Res. 2006;53:16-21.

9. Sautebin L. A cosmetovigilance survey in Europe. Pharmacol Res. 2007;55:455-60.

10. Vigan M, Castelain F. Cosmetovigilance: definition, regulation and use "in practice". Eur J Dermatol. 2014;24:643-9.

11. Amasa W, Santiago D, Mekonen S, Ambelu A. Are cosmetics used in developing countries safe? Use and dermal irritation of body care products in Jimma Town, South western Ethiopia. J Toxicol. 2012. doi:10.1155/2012/204830.

12. Echols MA. Food safety regulation in the European Union and the United States: different cultures, different laws. Colum J Eur L. 1998;4:525.

13. Marie L, Louise U, Jorgen S. Changes in European legislation make it timely to introduce a transparent market surveillance system for cosmetics. Acta Derm Venereol. 2007;87:485-92.

14. Tim L, Sanford L, Pamela L. "Hidden liabilities, market risk and drivers of change in the cosmetics and personal care products industry," Beneath the Skin, Investor in Environmental Health Network. 2007. http://iehn.org/filesalt/IEHNCosmeticsReport Fin.pdf. Accessed May, 2015.

15. EWG. "Campaign for Safe Cosmetics Report: toxic chemicals found in kid's bath products," Environmental Working Group, 2009. http:// www.ewg.org/report/toxic-tub/31209. Accessed Nov, 2015.

16. Frasca J. Cosmetics testing ensures safety for the public. 2010. http://www.prlog.org/10558136cosmetics-testing-ensures-safety-for-the-public.html. Accessed Nov, 2015.

17. Cortez-Pereira CS, Baby AR, Velasco MV. Fragrance technology for the dermatologist-a review and practical application. J Cosmet Dermatol. 2010;9:230-41.

18. Mansor N, Ali DE, Yaacob MR. Cosmetic usage in Malaysia: understanding of the major determinants affecting the users. Int J Bus Soc Sci. 2010;3:273-81.

19. Dibaba H, Yadesa D, Legesse B, et al. Cosmetics utilization pattern and related adverse reactions among female university students. Int J Pharma Sci Res. 2013;4:997-1004. 
20. Meharie BG, Ambaye AS, Thaimanot YM, et al. A cross sectional study on assessment of cosmetics utilization and self-reported adverse reactions among Wollo University, Dessie Campus Female Students, Dessie, North East Ethiopia. Eur J Pharm Med Res. 2014;2:49-63.

21. Central Statistical Agency: Ethiopia Demographic and Health Survey. Addis Ababa, Ethiopia; 2011. https://dhsprogram.com/pubs/pdf/FR255/FR255. pdf. Accessed Mar, 2015.

22. Degroot AC, Nater JP, Van der lendes R, et al. Adverse effects of cosmetics and toiletries: a retrospective study in the general population. Int J Cosmet Sci. 1987;9:255-9.

23. Consumer's Association. Reactions of the skin to cosmetic and Toiletry Products. Consumer's Association survey. London: Pharmaceutical Press; 1979.

24. Gisele Huf G, Rito PN, Villas Bôas MHS. Adverse reactions to cosmetic products and the Notification System in Health Surveillance: a survey. Rev Bras Epidemiol. 2013;16:1017-20.

25. Cosmetics and your health. http://www. womenshealth.gov/publications/ourpublications/ factsheet/cosmetics-your-health.pdf. Accessed Mar 20, 2016.
26. Bianchi A, Cantù P, Firenzuoli $\mathrm{F}$, et al. Rhabdomyolysiscaused by Commiphoramukul, a natural lipid-lowering agent. Ann Pharmacother. 2004;38:1222-5.

27. Bottenberg MM, Wall GC, Harvey RL, et al. Oral aloevera induced hepatitis. Ann Pharmacother. 2007;41:1740-3.

28. Boullata JI, McDonnell PJ, Oliva CD. Anaphylactic reaction to a dietary supplement containing willow bark. Ann Pharmacother. 2003;37:832-5.

29. Richard CL, Jurgens TM. Effects of natural health products on blood pressure. Ann Pharmacother. 2005;39:712-20.

30. Sleeper RB, Kennedy SM. Adverse reaction to a dietary supplement in an elderly patient. Ann Pharmacother. 2003;37:83-6.

31. World Health Organization. WHO guidelines on safety monitoring of herbal medicines in pharmacovigilance systems. Geneva: World Health Organization, 2004. http://apps.who.int/medicine docs/documents/s7148e/s7148e.pdf. Accessed Nov, 2015. 